\title{
Respon Tanaman Kakao (Theobroma cacao L.) Terhadap Pemberian Pupuk Kascing
}

\author{
${ }^{1}$ Irhantoro Adi Wibowo, ${ }^{2}$ Yulistiati Nengsih, dan ${ }^{2}$ Hayata \\ ${ }^{1}$ Alumni Program Studi Agroteknologi, Fakultas Pertanian, Universitas Batanghari \\ ${ }^{2}$ Program Studi Agroteknologi, Fakultas Pertanian, Universitas Batanghari \\ Jl. Slamet Riyadi No.1, Kota Jambi, Jambi 36122 \\ ${ }^{1}$ e-mail korensponden : irhantoro.adhi@gmail.com
}

\begin{abstract}
The growth of cocoa seedlings is influenced by the application of vermicompost fertilizer to the planting medium. The use of vermicompost in various doses of planting media can support the growth of cocoa plants. This study aims to determine the effect of giving several doses of vermicompost fertilizer on the growth of cocoa (Theobroma cacao L.). The research was conducted at nursery Citraland NGK Jambi which is located at Ismail Malik street Rt 046, Mayang Mangurai Village, Alam Barajo District, Jambi from January 2020 to May 2020. This research was conducted using a Completely Randomized Design (CRD) with vermicompost fertilizer treatment design consisting of 4 doses, namely $k 0$ (Not given vermicompost fertilizer), $k 1$ (vermicompost fertilizer $300 \mathrm{~g}_{\text {polybag }}^{-1}$ ), $\mathrm{k} 2$ (vermicompost fertilizer $600 \mathrm{~g}$ polybag ${ }^{-1}$ ), $\mathrm{k} 3$ (vermicompost fertilizer $900 \mathrm{~g}$ polybag $\left.^{-1}\right)$. Parameters observed were plant height, stem diameter, shoot dry weight, root dry weight and root crown ratio. The results showed that there was a significant effect of vermicompost fertilizer in several doses on plant height parameters (cm), but the parameters of stem diameter $(\mathrm{mm})$, shoot dry weight, root dry weight, and root canopy ratio showed no significant effect.

Keywords: cocoa, organic fertilizer, vermicompost
\end{abstract}

Abstrak. Pertumbuhan bibit kakao dipengaruhi oleh pemberian pupuk kascing pada media tanam. Penggunaan kascing pada media tanam dengan berbagai dosis mampu menunjang petumbuhan tanaman kakao. Penelitian ini bertujuan untuk mengetahui pengaruh pemberian beberapa dosis pupuk kascing pada pertumbuhan tanaman kakao (Theobroma cacao L.). Penelitian dilakukan di nursery Citraland NGK Jambi yang beralamat di jalan Ismail Malik RT 046, Kelurahan Mayang Mangurai Kecamatan Alam Barajo, Jambi pada bulan Januari 2020 sampai dengan Mei 2020.Penelitian ini dilakukan dengan menggunakan Rancangan Lingkungan Rancangan Acak Lengkap (RAL) dengan rancangan perlakuan pupuk kascing yang terdiri dari 4 dosis yaitu k0 (Tidak diberi pupuk kascing), k1 (Pupuk kascing 300 g polybag $^{-1}$ ), k2 (Pupuk kascing $600 \mathrm{~g} \mathrm{polybag}^{-}$ ${ }^{1}$ ), k3 (Pupuk kascing $900 \mathrm{~g}$ polybag $^{-1}$ ). Parameter yang diamati tinggi tanaman, diameter batang, bobot kering tajuk, bobot kering akar dan nisbah tajuk akar. Hasil penelitian menunjukkan terdapat pengaruh nyata pemberian pupuk kascing dalam beberapa dosis terhadap parameter tinggi tanaman $(\mathrm{cm})$, namun pada parameter diameter batang (mm), bobot kering tajuk, bobot kering akar, dan nisbah tajuk akar menunjukkan pengaruh tidak nyata.

Kata kunci : kakao, pupuk organik, kascing.

\section{PENDAHULUAN}

Indonesia merupakan salah satu negara penghasil kakao terbesar di dunia, namun produktivitas dan mutunya masih rendah. Rendahnya produktivitas dan mutu kakao di Indonesia selain menimbulkan kerugian yang cukup besar dipasaran dunia, tapi juga berdampak terhadap pendapatan petani kakao di Indonesia, Produktivitas kakao secara nasional mengalami penurunan sepanjang tahun.

Beberapa tahapan untuk memulai budidaya kakao yang baik adalah mempersiapkan bahan tanam di tempat pembibitan, hal itu merupakan usaha untuk mendukung pengembangan tanaman kakao agar berhasil dengan baik. Bahan tanam adalah hal yang sangat krusial dalam budidaya kakao, mengingat waktu yang diperlukan untuk tanaman dapat menghasilkan juga relatif lama, yaitu hampir lima tahun. Oleh sebab itu, bibit merupakan hal yang cukup penting dalam menentukan keberhasilan budidaya kakao (Marru dan Halomoan, 2015).

Salah satu usaha untuk meningkatkan kualitas dan kuantitas produksi kakao adalah dengan memperhatikan aspek budidaya tanaman kakao dari awal pembibitan. Untuk memperoleh bibit dengan mutu yang baik, maka benih yang digunakan adalah berasal dari benih kakao yang unggul. Pertumbuhan dan perkembangan bibit kakao pada masa pembibitan sangat erat kaitannya dengan pemupukan. Tujuan dari dilakukannya pemupukan adalah untuk memelihara atau memperbaiki struktur dan kesuburan tanah, sehingga bibit dapat menyerap nutrisi dengan baik dan bibit dapat tumbuh dengan subur dan sehat. Alasan dilakukannya pemupukan adalah untuk mengganti kehilangan unsur hara pada tanah serta untuk meningkatkan pertumbuhan dan perkembangan tanaman. (Roesmarkam dan Yuwono, 2002).

Kascing adalah kotoran cacing tanah yang dapat digunakan untuk meningkatkan kesuburan dan produktivitas tanah (Kusnadi, 1999). Kascing sebagai pupuk dapat memperbaiki struktur tanah dan dapat mempertahankan kestabilan serta aerase tanah (Khrisnawati, 2003). Selain dari pada itu kascing juga menyumbangkan unsur hara, dan mengandung banyak mikroorganisme yang membantu mempercepat ketersediaan 
unsur hara. Pengaplikasian kascing sebanyak 3,5 ton per hektar sangat cocok dilakukan pada tanah yang memiliki ketersediaan C-Organik (karbon organik) rendah seperti pada umumnya tanah-tanah inceptisol karena pada dosis tersebut dapat menjadikan rasio $\mathrm{C} / \mathrm{N}$ menjadi rendah dan $\mathrm{pH}$ tanah mendekati rata - rata 6,8 (Hamidah, 2010).

Tujuan penelitian ini adalah mengetahui adanya respon dari tanaman kakao terhadap pemberian pupuk kascing sehingga mampu meningkatkan pertumbuhan.

Pada penelitian sebelumnya yang dilakukan oleh Arlen dan Hafiz (2018) tentang pengaruh pemberian dosis pupuk kascing dan pupuk NPK terhadap pertumbuhan bibit tanaman kopi Arabika (Coffea arabica L.) pemberian pupuk kascing dosis $25 \mathrm{~g}$ polybag ${ }^{-1}$ yang diberikan sebanyak 12 kali dalam 3 bulan memberikan respon pertumbuhan terbaik pada bibit kopi arabika.

Pada penelitian lain yang dilakukan oleh Ramadhaini, Halus dan Marlina (2017) pupuk kascing diujikan terhadap pertumbuhan kedelaiberpengaruh sangat nyata pada dosis $81 \mathrm{~g}$ polybag $^{-1}$ yang diberikan selama $12 \mathrm{kali}$ dalam 3 bulan terhadap tinggi tanaman, jumlah polong, jumlah bintil akar, jumlah biji/100 polong dan berat 100 biji.

Berdasarkan uraian di atas, telah teruji pupuk kascing memiliki kemampuan untuk meningkatkan pertumbuhan bibit tanaman. Untuk itu penulis melakukan penelitian tentang respon tanaman kakao (Theobroma cacao L.) terhadap pemberian pupuk kascing.

\section{METODE PENELITIAN}

Penelitian dilakukan di nursery Citraland NGK Jambi yang beralamat di jalan Ismail Malik RT 046, Kelurahan Mayang Mangurai Kecamatan Alam Barajo, Jambi pada bulan Januari 2020 sampai dengan Mei 2020. Bahan yang digunakan dalam penelitian ini adalah bibit kakao jenis lindak yang berumur 2 bulan, pupuk kascing More Vermicompost (merek dagang), polybag $30 \times 35 \mathrm{~cm}$, tanah mineral dan pasir untuk media tanam dalam polybag, paranet $25 \%$, papan dan kayu. Alat yang digunakan dalam penelitian ini adalah timbangan digital, penggaris, $\mathrm{pH}$ meter, jangka sorong, dan alat tulis.

Penelitian ini dilakukan dengan menggunakan Rancangan Lingkungan Rancangan Acak Lengkap (RAL) dengan rancangan perlakuan pupuk kascing yang terdiri dari 4 dosis yaitu :k0 (kontrol), k1 (pupuk kascing $300 \mathrm{~g}$ polybag $^{-1}$ ), k2 (pupuk kascing $600 \mathrm{~g}^{\text {polybag }}{ }^{-1}$ ), k3 (pupuk kascing $900 \mathrm{~g}$ polybag ${ }^{-1}$ ). Setiap perlakuan terdapat 3 ulangan, sehingga diperoleh 12 unit satuan percobaan, setiap unit satuan percobaan terdiri dari 8 tanaman dan 4 tanaman dijadikan sampel, sehingga diperoleh total 96 tanaman.

\section{Pelaksanaan Penelitian}

Tempat penelitian yang dipilih adalah areal datar, terbuka dan dekat dengan sumber air. Areal yang digunakan untuk penelitian terlebih dahulu dibersihkan dari gulma dan sampah. Dibuat naungan dengan ketinggian $180 \mathrm{~cm}$ pada sisi timur, $150 \mathrm{~cm}$ pada sisi barat dan disekelilingnya dibuat pagar dengan papan untuk menghindari hewan pengganggu.

Polybag diisi dengan tanah mineral dan pasir dengan perbandingan 2:1. Kemudian polybag diisi sesuai perlakuan dengan komposisi sebagai berikut $\mathrm{k} 0=3 \mathrm{~kg}$ tanah + pasir tanpa kascing, $\mathrm{k} 1=2.700 \mathrm{~g}$ media tanam +300 g pupuk kascing, $\mathrm{k} 2=2.400 \mathrm{~g}$ media tanam $+600 \mathrm{~g}$ pupuk kascing, $\mathrm{k} 3=2.100 \mathrm{~g}$ media tanam $+900 \mathrm{~g}$ pupuk kascing. Bibit kakao yang digunakan adalah bibit yang telah tersedia berumur 2 bulan. Bibit kakao dipilih yang memiliki pertumbuhan yang seragam dan bebas dari hama dan penyakit tanaman. Bibit kakao kemudian ditanam pada polybag yang telah diisi media tanam sesuai perlakuan. Penanaman bibit kakao diikuti dengan pemasangan ajir untuk acuan pengukuran tinggi tanaman. Pemeliharaan tanamana meliputi penyiraman, penyiangan gulma, pengendalian hama dan penyakit. Penyiraman dilakukan dua kali sehari yaitu pada pagi dan sore hari.

\section{Parameter yang Diamati \\ Tinggi Tanaman $(\mathbf{c m})$}

Pengukuran tinggi tanaman awal dilakukan 3 hari setelah tanam, kemudian pengukuran tinggi tanaman dilakukan setiap 2 minggu sekali sampai akhir penelitian yaitu 12 MST.

\section{Diameter Batang}

Pengukuran diameter batang dilakukan pada akhir penelitian menggunakan jangka sorong. Diameter batang diukur $5 \mathrm{~cm}$ diatas media tanam.

\section{Bobot Kering Tajuk}

Bobot kering tajuk diperoleh dengan cara menimbang bagian tajuk tanaman mulai dari leher akar sampai ke pucuk yang telah dikering ovenkan pada suhu $100^{\circ} \mathrm{C}$ selama $2 \times 24$ jam.

\section{Bobot Kering Akar}

Bobot kering akar diperoleh dengan cara menimbang bagian akar tanaman mulai dari leher sampai ke ujung akar yang telah dikering ovenkan pada suhu $100^{\circ} \mathrm{C}$ selama $2 \times 24$ jam. 


\section{Nisbah Tajuk Akar (NTA)}

Perhitungan nisbah tajuk akar didasarkan pada data hasil pengukuran bobot kering tajuk dan bobot kering akar.

Rumus perhitungan:

$N T A=\frac{B K T}{B K A}$

Keterangan :

NTA : Nisbah Tajuk Akar

BKT : Berat Kering Tajuk

BKA : Berat Kering Akar

\section{Pengukuran pH Tanah}

Pengukuran $\mathrm{pH}$ tanah dilakukan diawal dan diakhir penelitian menggunakan $\mathrm{pH}$ meter dengan cara menancapkan ujung $\mathrm{pH}$ meter ke dalam media tanam hingga angka $\mathrm{pH}$ meter stabil di layar.

\section{Sifat Fisik Tanah}

Pengamatan sifat fisik tanah yang meliputi warna tanah menggunakan Buku Munsell Soil Chart dan struktur tanah secara manual.

\section{Pengukuran Kadar N dan P}

Pengukuran kadar unsur hara Nitrogen $(\mathrm{N})$ dan Fosfor $(\mathrm{P})$ dilakukan diakhir penelitian.

\section{Analisis Data}

Untuk mengetahui pengaruh pupuk kascing terhadap parameter yang diamati, maka data yang diperoleh dari hasil pengamatan dianalisis secara statistik menggunakan analisis ragam dan dilakukan uji lanjut menggunakan uji DNMRT pada taraf nyata $5 \%$.

\section{HASIL DAN PEMBAHASAN}

Berdasarkan hasil pengamatan dan analisis ragam menunjukkan bahwa pemberian pupuk kascing dengan berbagai dosis, memberikan pengaruh nyata pada tinggi tanaman, namun berpengaruh tidak nyata pada diameter batang, bobot kering tajuk, bobot kering akar dan nisbah tajuk akar.

Tabel 1. Rata-rata Tinggi Tanaman Kakao Dengan Perlakuan Berbagai Dosis Pupuk Kascing.

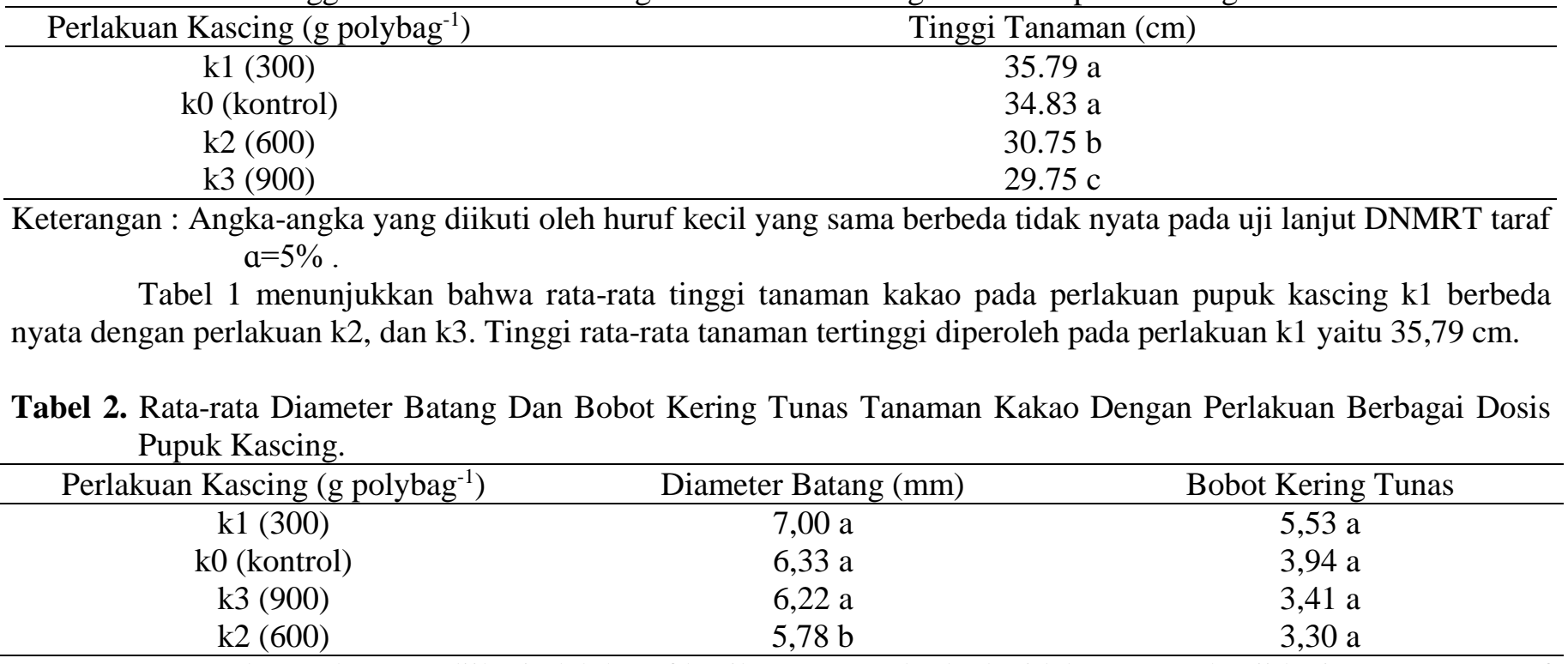

Keterangan : Angka-angka yang diikuti oleh huruf kecil yang sama berbeda tidak nyata pada uji lanjut DNMRT taraf $\mathrm{a}=5 \%$.

Tabel 2 menunjukkan bahwa rata-rata diameter batang dan bobot kering tajuk tanaman kakao pada semua perlakuan pupuk kascing berbeda tidak nyata. Rata-rata diameter batang tanaman tertinggi diperoleh pada perlakuan $\mathrm{k} 1$ yaitu 7,00 $\mathrm{mm}$ dan rata-rata bobot kering tunas tanaman $5,53 \mathrm{~g}$. 
Tabel 3. Rata-rata Bobot Kering Akar Tanaman Kakao Kakao Dengan Perlakuan Berbagai Dosis Pupuk Kascing.

\begin{tabular}{cc}
\hline Perlakuan Kascing $\left(\mathrm{g} \mathrm{polybag}^{-1}\right)$ & Bobot Kering Akar $(\mathrm{g})$ \\
\hline $\mathrm{k} 1(300)$ & $1,20 \mathrm{a}$ \\
$\mathrm{k} 2(600)$ & $0,98 \mathrm{a}$ \\
$\mathrm{k} 0$ (kontrol) & $0,91 \mathrm{a}$ \\
$\mathrm{k} 3(900)$ & $0,76 \mathrm{a}$ \\
\hline
\end{tabular}

Keterangan : Angka-angka yang diikuti oleh huruf kecil yang sama berbeda tidak nyata pada uji lanjut DNMRT taraf $a=5 \%$.

Tabel 3 menunjukkan bahwa rata-rata bobot kering akar tanaman kakao pada semua perlakuan pupuk kascing berbeda tidak nyata. Rata-rata bobot kering akar tanaman tertinggi diperoleh pada perlakuan k1 yaitu 1,20 g.

Tabel 4. Rata-rata Nisbah Tajuk Akar Tanaman Kakao Kakao Dengan Perlakuan Berbagai Dosis Pupuk Kascing.

\begin{tabular}{cc}
\hline Perlakuan Kascing $\left(\mathrm{g} \mathrm{polybag}^{-1}\right)$ & Rata-rata NTA \\
\hline k1 (300) & $4,54 \mathrm{a}$ \\
k3 (900) & $4,50 \mathrm{a}$ \\
k0 (kontrol) & $4,35 \mathrm{a}$ \\
k2 (600) & $3,53 \mathrm{a}$ \\
\hline
\end{tabular}

Keterangan : Angka-angka yang diikuti oleh huruf kecil yang sama berbeda tidak nyata pada uji lanjut DNMRT taraf $a=5 \%$.

Tabel 4 menunjukkan bahwa rata-rata nisbah tajuk akar tanaman kakao pada semua perlakuan pupuk kascing berbeda tidak nyata. Rata-rata nisbah tajuk akar tanaman tertinggi diperoleh pada perlakuan k1 yaitu 4,54 dan terdapat peningkatan nisbah tajuk akar tanaman kakao sebesar 22,44\% bila dibandingkan dengan k0.

Tabel 5. pH dan Warna Media Tanam Dengan Berbagai Dosis Pupuk Kascing.

\begin{tabular}{ccc}
\hline $\begin{array}{c}\text { Perlakuan kascing }(\mathrm{g} \\
\left.\text { polybag }^{-1}\right)\end{array}$ & $\mathrm{pH}$ & Warna media \\
\hline $\mathrm{k} 0\left(\mathrm{kontrol}^{2}\right)$ & 5,5 & 7,5 YR 4/6 = Strong Brown \\
$\mathrm{k} 1(300)$ & 5,8 & 7,5 YR 4/4 = Brown \\
$\mathrm{k} 2(600)$ & 6 & 7,5 YR 3/3 = Dark Brown \\
$\mathrm{k} 3(900)$ & 6 & 7,5 YR 2,5/1 = Black \\
\hline
\end{tabular}

Tabel 5 menunjukkan bahwa pupuk kascing dapat menaikkan $\mathrm{pH}$ media tanam. Nilai pH media tanam pada perlakuan $\mathrm{k} 0(5,5)$ merupakan perlakuan dengan nilai $\mathrm{pH}$ terendah dan pada perlakuan $\mathrm{k} 2$ dan $\mathrm{k} 3$ (6) merupakan nilai $\mathrm{pH}$ tertinggi.

Berdasarkan warna media tanam diketahui bahwa semakin banyak dosis pupuk kascing yang dicampurkan ke media tanam, maka warna media akan berubah menjadi gelap.

Tabel 6. Hasil Analisis Laboratorium

\begin{tabular}{cccc}
\hline No. & Perlakuan & N total & P HCl 25\% \\
& & $\%$ & $\left(\mathrm{mg} \mathrm{P}_{2} \mathrm{O}_{5} 100 \mathrm{~g}^{-1}\right)$ \\
\hline 1 & $\mathrm{k} 0$ & 0,21 & 47,93 \\
2 & $\mathrm{k} 1$ & 0,31 & 86,79 \\
3 & $\mathrm{k} 2$ & 0,37 & 155,47 \\
4 & $\mathrm{k} 3$ & 0,54 & 161,41 \\
\hline
\end{tabular}

Sumber : Laboratorium BPTP Jambi.

Berdasarkan Tabel 6 diketahui bahwa semakin banyak dosis pupuk kascing yang dicampurkan ke media tanam, maka kandungan unsur $\mathrm{N}$ dan $\mathrm{P}$ juga akan semakin meningkat.

Hasil analisis ragam menunjukkan bahwa perlakuan dosis pupuk kascing berpengaruh nyata terhadap parameter tinggi tanaman. Uji DNMRT pada selang kepercayaan 95\% menunjukan bahwa perlakuan dosis pupuk kascing k1 (300 g polybag $\left.^{-1}\right)$ memberikan hasil rata-rata tertinggi dibanding perlakuan lainnya pada tinggi tanaman.

Rata-rata tinggi tanaman tertinggi diperoleh dari perlakuan k1 yaitu $35,79 \mathrm{~cm}$. Hal ini dikarenakan pemberian pupuk kascing dapat memperbaiki sifat fisik, biologi, dan kimia tanah. Sifat fisik terlihat dari perubahan struktur media tanam dari padat menjadi remah dan warna menjadi gelap akibat aktifitas mikroorganisme di dalam 
tanah. Struktur tanah yang remah memungkinkan akar tanaman untuk menyerap unsur hara dengan baik. Sifat kimia terlihat dari perubahan $\mathrm{pH}$ tanah dari 5,5 menjadi 6 .

Perubahan struktur tanah dari padat menjadi remah memungkinkan akar tanaman berkembang dengan baik, sehingga memudahkan tanaman dalam menyerap unsur hara yang ada di dalam media tanam. Unsur $\mathrm{N}$, P, dan $\mathrm{K}$ yang diserap oleh akar tanaman merupakan unsur hara yang mutlak dibutuhkan dalam pertumbuhan tanaman.

Unsur $\mathrm{N}$ yang tersedia di dalam media tanam dapat meningkatkan pertumbuhan vegetatif tanaman secara keseluruhan, khususnya pada pertumbuhan akar, batang, dan daun. Hal ini sejalan dengan pendapat Foth (1978) menjelaskan bahwa $\mathrm{N}$ berperan besar bagi pertumbuhan vegetatif tanaman, merangsang pertumbuhan dan mempercepat kedewasaan lebih awal, yaitu pembentukan organ-organ tanaman, termasuk di dalamnya pembentukan dan pertambahan tinggi batang. Salisbury dan Ross (1995) menyatakan, pada fase vegetatif di dalam tanaman terjadi sirkulasi $\mathrm{N}$ dari akar ke daun dan sebaliknya untuk menyalurkan $\mathrm{N}$ ke organ pengguna agar tidak terjadi kekurangan $\mathrm{N}$ di organ tumbuhan, sehingga jika tanaman kekurangan $\mathrm{N}$ maka pembentukan batang akan terganggu. Menurut Jumin (2002) bahwa batang merupakan daerah akumulasi pertumbuhan tanaman khususnya pada tanaman yang lebih muda sehingga dengan adanya unsur hara yang dapat mendorong pertumbuhan vegetatif tanaman diantaranya pembentukan klorofil pada daun sehingga akan memacu laju fotosintesis. Semakin tinggi laju fotosintesis maka fotosintat yang dihasilkan akhirnya akan meningkatkan tinggi tanaman. Disamping unsur N, keberadaan unsur P, K yang terkandung dalam kascing turut mempengaruhi tinggi tanaman kakao. Menurut Foth (1978) meskipun fungsi nitrogen yang paling utama adalah mendorong pertumbuhan vegetatif tanaman, pertumbuhan ini tidak akan berlangsung tanpa adanya $\mathrm{P}, \mathrm{K}$ dan unsur utama lainnya yang tersedia. Unsur P memiliki peran sebagai bahan bakar universal kegiatan biokimia dalam sel, sehingga jika tanaman kekurangan unsur P pembelahan selnya terhambat dan pertumbuhannya kerdil. Unsur K memiliki peran mempercepat penyerapan air dan unsur hara dari media tanam oleh tanaman. Pada parameter tinggi tanaman menunjukkan adanya pengaruh pemberian pupuk kascing terhadap pertambahan tinggi tanaman. Salisbury dan Ross (1995) menyatakan bahwa pertambahan ukuran organ tanaman secara keseluruhan merupakan hasil dari pertambahan ukuran organ-organ tanaman akibat dari pertambahan jaringan sel yang dihasilkan oleh pertambahan ukuran sel.

Perubahan pada sifat kimia dapat dilihat dari adanya perubahan $\mathrm{pH}$ tanah, dari nilai 5,5 (k0) meningkat menjadi 6 (k2 dan $\mathrm{k} 3$ ) atau mendekati netral. Kondisi $\mathrm{pH}$ yang mendekati netral mempengaruhi ketersediaan unsur hara dalam media tanam, sehingga dapat diserap oleh akar tanaman. Menurut Campbell dan Reece (2008), pH merupakan faktor penting karena berpengaruh terhadap ketersediaan mineral dalam tanah yang dibutuhkan oleh tanaman.

Perubahan pada sifat biologi ditunjukkan dengan aktifitas mikroorganisme dalam media tanam yang mempengaruhi ketersediaan bahan organik. Tanah yang berwarna gelap menunjukkan kandungan bahan organik yang tinggi. Sedangkan tanah yang berwarna coklat (agak terang) menunjukkan kandungan bahan organik yang rendah.

Hasil analisis ragam terhadap diameter batang, bobot kering tunas, bobot kering akar, dan nisbah tajuk akar menunjukkan hasil berpengaruh tidak nyata. Hal ini dikarenakan bibit kakao bukan berasal dari bibit unggul atau bibit yang tidak bersertifikat sehingga terjadi segregasi yang mengakibatkan respon terhadap penyerapan unsur hara berbeda-beda antar bibit. Selain itu sifat genetis tanaman juga mempengaruhi pertumbuhan tanaman kakao, karena pada parameter pertambahan tinggi tanaman kakao, pemberian pupuk kascing dengan beberapa dosis berbeda menunjukkan pengaruh yang nyata. Hal ini sependapat dengan pernyataan Lakitan (2010) yang menyatakan bahwa pertumbuhan sistem perakaran akan menyimpang dari kondisi idealnya jika kondisi tanah tempat tumbuhnya tidak optimal, namun apabila terjadi kebalikannya, maka dapat dipastikan sistem perakaran tanaman sepenuhnya dipengaruhi oleh faktor genetis. Dari pupuk kascing yang digunakan belum diketahui SNI-nya dan nilai $\mathrm{C} / \mathrm{N}$ rasio yang masih tinggi mengakibatkan kandungan unsur hara yang dapat diserap oleh tanaman menjadi sedikit.

\section{KESIMPULAN}

Pemberian pupuk kascing pada tanaman kakao dengan dosis yang berbeda memberikan pengaruh nyata pada tinggi tanaman, namun berpengaruh tidak nyata terhadap diameter batang, bobot kering tajuk, bobot kering akar, dan nisbah tajuk akar bibit kakao.

Perlakuan k1 menghasilkan pertumbuhan tinggi tanaman tertinggi yakni $35,79 \mathrm{~cm}$, diameter batang terbesar yakni 7,00, bobot kering tunas tertinggi yaitu 5,53 g, bobot kering akar tertinggi yakni 1,20 g dan nisbah tajuk akar tertinggi yaitu 4,54. 


\section{DAFTAR PUSTAKA}

Arlen, F. dan Hafiz, F. 2018. Pengaruh Pemberian Dosis Pupuk Kascing dan Pupuk NPK Terhadap Pertumbuhan Bibit Tanaman Kopi Arabika (Coffea https://jom.unri.ac.id/index.php/JOMFAPERTA/article/view/24777. JOM FAPERTA vol. 6 Edisi 1. Diakes pada Desember 2019.

Campbell, N. A. dan J. B. Reece. 2008. Biologi Edisi Delapan Jilid 2. Erlangga. Jakarta.

Foth, H. D. 1978. Dasar-Dasar Ilmu Tanah. diterjemahkan oleh Soenarto. Penerbit Erlangga. Jakarta.

Hamidah, M. 2010. Kascing Sebagai Pupuk Organik. http://hamidahmamur.wordpress.com/prihal/kascing-sebagaipupuk-organik/, diakses pada Desember 2019.

Jumin, H. B. 2002. Dasar-Dasar Agronomi. Rajawali. Jakarta.

Khrisnawati, D. 2003. Pengaruh Pemberian Pupuk Kascing Terhadap Pertumbuhan vegetatif Tanaman kentang. KAPPA. Surabaya.

Kusnadi, M. H. 1999. Respon Kedelai Terhadap Inokulasi Jamur MVA dan Kascing Pada Ketersediaan Air Tanah Yang Berbeda Selama periode Pengisian Polong. Fakultas Pertanian. UNPAD. Bandung.

Lakitan, B. 2010. Dasar-Dasar Fisiologi Tumbuhan. Raja Grafindo Persada. Jakarta.

Marru, D. dan Halomoan H. S. 2015. Kakao. Graha Ilmu. Yogyakarta.

Ramadhaini, Halus. S., dan Marlina. 2017. Pemberian Pupuk Kascing Terhadap Pertumbuhan dan Hasil Tanaman kedelai (Glycine max L.). http://jurnal.umuslim.ac.id/index.php/ah/article/view/824. Agrotropika Hayati vol. 4 no. 3, diakses pada Desember 2019.

Roesmarkam, A. dan N. W. Yuwono. 2002. Ilmu Kesuburan Tanah. Kanisius. Yogyakarta.

Salisbury, F. B dan C. W. Ross. 1997. Fisiologi Tumbuhan. Jilid 1 Terjemahan Dian Rukmana dan Sumaryono. ITB. Bandung. 